\title{
Cancer and exercise immunity: 6th series of scientific evidence
}

Yong-Seok Jee (iD https://orcid.org/0000-0001-6797-0843

All of the previous editorials in this series reported the benefits of exercise in improving immune function. However, the target of exercise rehabilitation for immunity enhancement was limited to general patients or normal people, not cancer patients. It is common knowledge that exercise is important for everyone, but what is less commonly known is that exercise is especially important for cancer patients. As is the case with most patients suffering from any kind of disease, immune function in cancer patients is significantly impaired, so special measures are required to protect it. Among the various theories, the ones that appear most credible state that moderate exercise provides good conditions for creating an intramuscular environment for activating immune function.

In 2016, Pedersen and his colleagues conducted an interesting research study on cancer and exercise. Mice with various types of cancer, including skin, lung, and liver cancer, were used to test the anticancer effects of exercise by dividing them into two groups: One group ran about 4-7 km a day for 4 weeks on the wheel while the second group did not exercise. The results showed that no new cancers occurred in the group of mice that exercised, and the growth rate of cancer in mice that already had cancer was reduced by $60 \%$ compared to other groups. Even with strong anticancer drugs, it is not easy to reduce the rate of cancer growth by $60 \%$. How does exercise suppress cancer cells? The process of inhibiting cancer cell growth through exercise is as follows. When exercising, muscles release epinephrine, which triggers natural killer (NK) cells. These NK cells move into the blood and exert anticancer effects. In addition, when exercising, a cytokine called interleukin-6 (IL-6) is also released. IL-6 and various interleukins work directly with NK cells to attack cancer cells. As a result, the positive effect of slowing the growth rate of cancer cells can be obtained through exercise.

Recently, there have been several studies on the relationship between exercise and immune cells. According to several previous studies, the immune function of the human body can activate T, $\mathrm{B}$, and NK cells only by activating the musculoskeletal system. In other words, when exploring the possible mechanisms by which adaptation to exercise can occur, the immune system appears to be of particular importance because physical exercise exerts both systemic and local effects on the immune system. Now, it can be said that the era of preventing and treating cancer by increasing the body's immunity through exercise has arrived.

The first series is presented in J Exerc Rehabil 2019;15(3):339340, Available from: https://doi.org/10.12965/jer.1938302.151.

The second series is presented in J Exerc Rehabil 2020;16(2): 113-114, Available from: https://doi.org/10.12965/jer.2040178. 089.

The third series is presented in J Exerc Rehabil 2020;16(3): 205-206, Available from: https://doi.org/10.12965/jer.2040414. 207.

The forth series is presented in J Exerc Rehabil 2020;16(5):383384, Available from: https://doi.org/10.12965/jer.2040712.356.

The fifth series is presented in J Exerc Rehabil 2021;17(1):2-3, Available from: https://doi.org/10.12965/jer.2142042.021. 


\section{CONFLICT OF INTEREST}

No potential conflict of interest relevant to this article was reported.

\section{REFERENCE}

Pedersen L, Idorn M, Olofsson GH, Lauenborg B, Nookaew I, Hansen $\mathrm{RH}$, Johannesen HH, Becker JC, Pedersen KS, Dethlefsen C, Nielsen J,
Gehl J, Pedersen BK, Thor Straten P, Hojman P. Voluntary running suppresses tumor growth through epinephrine and IL-6-dependent NK cell mobilization and redistribution. Cell Metab 2016;23:554-562.

Research Institute of Sports and Industry Science, Hanseo University, 46 Hanseo 1-ro, Haemimyeon, Seosan 31962, Korea Email: jeeys@hanseo.ac.kr 